九州大学学術情報リポジトリ

Kyushu University Institutional Repository

\title{
NEW OR LITTLE KNOWN BEES OF JAPAN (HYMENOPTERA, APOIDEA) IV. SUPPLEMENTS TO ANDRENA (SIMANDRENA)
}

Tadauchi, 0samu

Hirashima, Yoshihiro

https://doi.org/10.5109/2438

出版情報: ESAKIA. 20，pp.81-92，1983-12-15. Entomological Laboratory，Faculty of Agriculture， Kyushu University

バージョン :

権利関係 : 


\title{
NEW OR LITTLE KNOWN BEES OF JAPAN (HYMENOPTERA, APOIDEA) IV. SUPPLEMENTS TO ANDRENA (SIMANDRENA)*
}

\author{
Osamu TADAuchi and Yoshiniro Hirashima \\ Entomological Laboratory, Faculty of Agriculture, \\ Kyushu University, Fukuoka 812, Japan
}

\begin{abstract}
Japanese species of the subgenus Simandrena of the genus Andrena are revised. Two new species, Andrena (Simandrena) yamato and A. (Simandrena) nippon, and a new subspecies, A. (Simandrena) opacifovea austroinsularis, are described. The male of A. (Simandrena) kerriae Hirashima is described for the first time. A key is presented for the Japanese species of Simandrena.
\end{abstract}

Japanese species of the subgenus Simandrena of the genus Andrena are revised primarily based on the material recently collected by Tadauchi. Our results reveal that four species of Simandrena are known to occur in Japan. Descriptions of two new species, Andrena (Simandrena) yamato and A. (Simandrena)nippon and a new subspecies A. (Simandrena) opacifovea austroinsularis are given in this paper.

We are grateful to Mr. H. Makihara of Forestry \& Forest Products Res. Institute, Mr. Y. Haneda of Ohno City, Fukui Pref., Dr. I. Togashi of Ishikawa Pref. College of Agriculture, Dr. R. Ishikawa of Tokyo Metropolitan Univ., Dr. Y. Maeta of Shimane Univ., Mr. K. Ôhara and Assoc. Prof. A. Nakanishi of Kyushu Univ., Dr. K. Nohara of Kyushu Tokai Univ., and Mr. S. Ikudome of Kagoshima Women's Junior College for their gift and loan of valuable specimens.

\section{KEY TO JAPANESE SPECIES OF Simandrena}

\section{Female}

1. Thorax covered with primarily pale yellowish brown hairs dorsally, frequently intermixed with brownish hairs on mesoscutum; propodeum long with large propodeal enclosure; metasomal terga finely tessellate, nearly impunctate or with very weak punctures

* Contribution from the Entomological Laboratory, Faculty of Agriculture, Kyushu University, Fukuoka (Ser. 3, No. 134). 
Thorax covered with fulvous hairs dorsally; propodeum shorter with smaller enclosure; metasomal terga densely punctate, although punctures small $\ldots \ldots \ldots \ldots \ldots \ldots . \ldots . \cdots 4$ Subapical margin of pronotum emarginate in the middle; pronotum with a median longitudinal line (obscure in opacifoveaaustroinsularis); mesoscutum tessellate, although sometimes very weakly so; wrinkles on apical portion of propodeal enclosure often weak; clypeus with an indication of median longi-

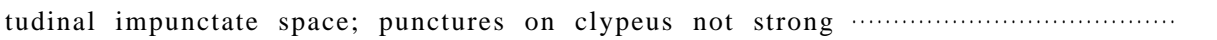
Subapical margin of pronotum entire or sometimes very weakly emarginate in the middle; pronotum without a median longitudinal line ; usually pronotum not tessellate except anterior portion; apical portion of propodeal enclosure distinctly wrinkled like basal portion, often transversely keeled at apex; metasomal terga nearly impunctate or with minute punctures; clypeus with rather strong and coarse punctures, usually without median impunctate line ...

yamato, new species

Larger, length 9-10 $\mathrm{mm}$; median line of pronotum distinct ; propodeal enclosure distinctly wrinkled; 1 st metasomal tergum nearly smooth and shining, with very weak punctures; vertex and mesoscutum with hairs paler ...............

opacifovea opacifovea Hirashima

Smaller, length 8-9 mm; median line of pronotum obscure ; propodeal enclosure weakly wrinkled; 1 st metasomal terga distinctly tessellate or lineolate, nearly impunctate or with microscopical punctures; hairs on vertex, mesoscutum and scutellum fuscous …....................... opacifovea austroinsularis, new subspecies Clypeus weakly convex, with a median longitudinal impunctate space transversely shagreened; process of labrum distinctly truncate, narrow ; mesoscutum densely punctate; propodeal enclosure strongly wrinkled, wrinkles distinct even on apical portion; metasomal terga very densely, distinctly punctate ; caudal

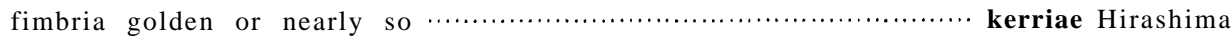

Clypeus well convex, distinctly punctate, with median longitudinal impunctate space, when present, smooth, shining ; process of labrum broader ; mesoscutum sparsely punctate; propodeal enclosure weakly wrinkled on basal portion only; metasomal terga with punctures weaker and sparser; caudal fimbria brownish

nippon, new species

\section{Male}

First flagellar segment about as long as broad, distinctly shorter than next

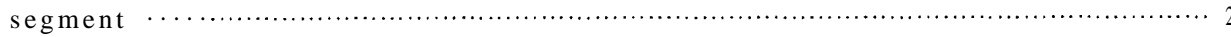
First flagellar segment at least one and half times as long as broad, about as

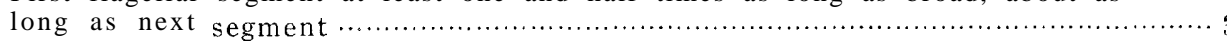

Smaller, length about $8 \mathrm{~mm}$; subapical margin of pronotum entire ; metasomal sternum 7 with apical lobes narrow; sternum 8 with apical lobe slender;

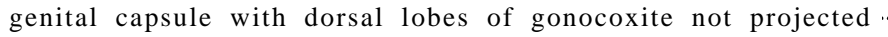

yamato, new species

Larger, length 8.5-9.5 $\mathrm{mm}$; subapical margin of pronotum emarginate ;metasomal sternum 7 with apical lobes broader, rounded; sternum 8 with apical lobe broad and widened apically; genital capsule with dorsal lobes of gonocoxite moderately produced $\ldots \ldots \ldots \ldots \ldots \ldots \ldots \ldots \ldots \ldots \ldots \ldots \ldots \ldots \ldots \ldots$ opacifovea Hirashima Clypeus with very dense, silvery white hairs ; clypeus with median longitudinal area transversely shagreened, propodeal enclosure wrinkled all over ;

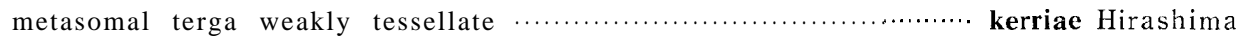
Clypeus with dirty pale hairs mixed with blackish ones; paraocular area and 
supra-antennal area mixed with blackish hairs; clypeus with median longitudinal area smooth and shiny; propodeal enclosure wrinkled at base only ; metasornal terga smooth and shiny $\ldots \ldots \ldots \ldots \ldots \ldots \ldots \ldots \ldots \ldots \ldots \ldots$ nippon, new species

\section{Andrena (Simandrena) yamato, new species}

Andrena (Simandrena) opacifovea Hirashima, 1952, Mushi, 24: 31, female and male, in part. (Description)

Andrena (Simandrena) opacifovea Hirashima, 1965, J. Fac. Agr., Kyushu Univ., 13: 497, female and male, in part. (Description)

Andrena opacifovea Hirashima is here divided into two species, opacifovea a $\mathrm{n} d$ yamato, new species. The two species may be separable by the characters given in the key. So far as the female is concerned, the most important morphological character which separates the two species is the pronotum, the subapical margin of which is emarginate in the middle and this emargination extends posteriorly as a median line in opacifovea. Hirashima (1965) overlooked this important character*.

Female: Smaller than opacifovea, length 8-9 $\mathrm{mm}$.

Integumental color: Flagellar segments 3-10 brownish to reddish brown below; metasomal terga and sterna brownish transparent apically.

Pubescence: Hairs on head nearly pale or sometimes slightly yellowish ; facial fovea brownish above and silvery below; mesoscutum with short, pale hairs and mixed with much sparser, longer, erect, brownish ones; hairs on scutellum long, brownish marginally; propodeal corbicula very well developed with dorsal fringe of yellowish, quite long, dense, well arranged hairs; dorsal face of propodeum with sparse yellowish hairs; trochanteral floccus imperfect, short, scanty ; tibia1 scopa scanty, composed of very short hairs; metasomal tergum 1 free of hairs medially; posterior margins of terga 2-4 with broad white hair bands, that of 2 nd broadly, that of 3rd narrowly interrupted medially; caudal fimbria pale brownish; metasomal sterna 1-2 with short, dense, erect hairs medially, sterna 2-5 with short, suberect, pale hairs posteriorly, with apical fringe very short.

Structure: Process of labrum moderate in size, twice as broad as long, entire. Clypeus tnore convex than in opacifovea, nearly smooth or basal half weakly tessellate, more shiny than in opacifovea, with medium-sized, more or less distinct, not dense, irregular punctures ; clypeus without a longitudinal impunctate space (with a longitudinal impunctate space in opacifovea). Lower paraocular area nearly smooth to very weakly tessellate, with weak punctures. Genal area with very narrow shiny space near eye and shagreened posteriorly. Facial fovea with upper end occupying more than two thirds of ocellocular

* Hirashima is grateful to Dr. R. W. Griinwaldt of München who told him in 1967 that this structure of the pronotum, although usually hidden by the head, may serve as a good diagnostic character to separate certain sibling species of Andrena. 
space (nearly full space in opacifovea). Malar space linear. Mandible short. Scape longer than flagellar segments I-3; flagellum with segment 1 shorter than 2 plus 3. Eyes with inner margins subparallel.

Pronotum very weakly tessellate, shiny, with weak, sparse punctures; pronotum with lateral suture slightly indicated, rather long, without humeral angle and lateral lugulae, subapical margin of pronotum not emarginate (emarginate in ofiacifovea) and pronotal line not indicated (well indicated in opacifovea). Mesoscutum less tessellate than in opacifovea with smaller, weaker, and sparser punctures than in opacifovea. Propodeal enclosure large, triangular, well defined, apical portion of propodeal enclosure distinctly wrinkled like basal portion (often weak in opacifovea), often transversely keeled at apex; dorsal face of propodeum roughened, corbicular area densely tessellate. Mes-
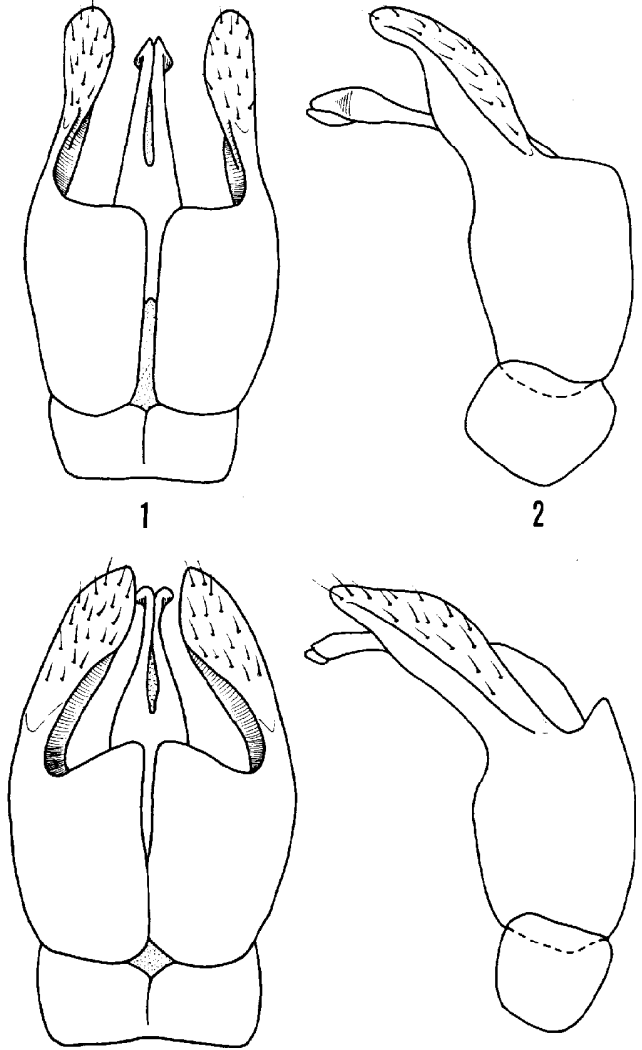

5

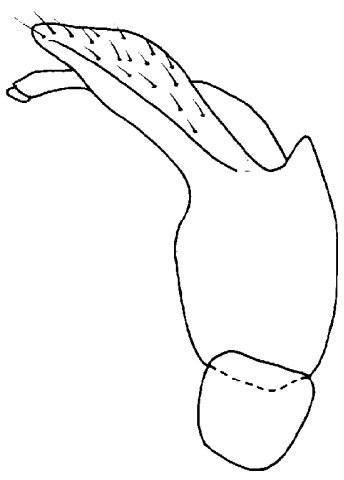

6

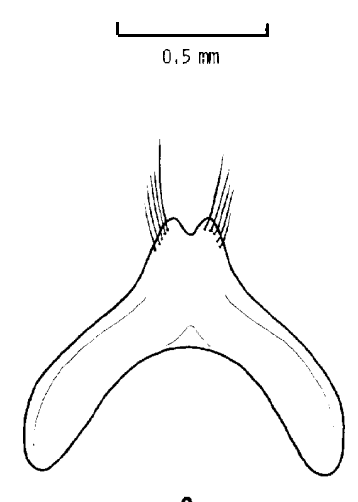

3

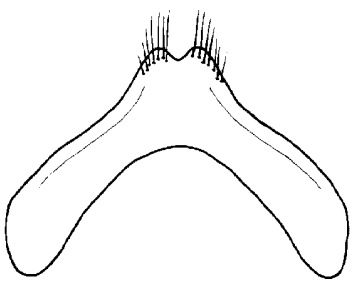

7

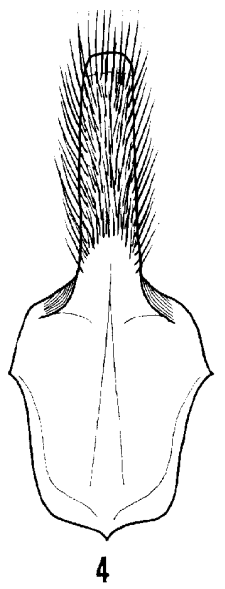

Figs. 1-8. Genital capsules and associated structures of Andrena(Simandrena) yamato, new species (1-4), and Andrena (Simandrena) ofiacifovea Hirashima (5-8). 1 and 5: dorsal views of genital capsules, 2 and 6: lateral views of the same, 3 and 7: 7 th sterna, 4 and 8: 8th sterna. 
episternum somewhat coarsely shagreened anteriorly, densely tessellate post eriorly.

Leg with middle basitarsus slightly expanded medially, hind basitarsus slightly tapering ; hind tibia short, strongly widened apically.

Metasomal tergum 1 weakly tessellate with sparse, microscopical punctures. weaker than in opacifovea, terga 2-4 finely tessellate all over, weakly shiny with slightly larger punctures denser on basal areas; apical depressions of terga well indicated. Pygidial plate narrow, acute apically (broad, blunt in opacifovea), with median area well raised. Sterna 1 weakly tessellate with small punctures, with U-shaped median emargination; sterna 2-6 finely tessellate with weak, dense punctures; posterior depressions of sterna not well indicated; gradulus only indicated on sternum 2.

Male: Smaller than opacifovea, length about $8 \mathrm{~mm}$.

Agrees with description of female except as follows (excluding usual sexual differences) : Head and thorax with hairs long, more or less dense, white; hairs on thorax not mixed with brownish ; metasomal terga 2-4 with indistinct whitish hair bands apically ; tergum 6 with sparse, pale yellowish hairs; clypeus very weakly to weakly tessellate, with more or less dense, coarse punctures ; scape equal to flagellar segments 1 plus 2 ; flagellum with segment 1 about as long as broad, distinctly shorter than next segments; eyes with inner margins divergent above; mesoscutum densely tessellate with small, sparse punctures posteriorly, nearly shagreened anteriorly ; sternum 7 (Fig. 3; cf. Fig. 7 for opacifovea) with apex emarginate, V-shaped, apical lobes narrow (broad and round in opacifovea), with sparse long hairs; sternum 8 (Fig. 4; cf. Fig. S for opacifovea) with apical lobe slender (broad and apex widened in opacifovea), with abundant, long hairs; genital capsule (Figs. 1-2; cf. Figs. 5-6 for opacifovea) with dorsal lobes of gonocoxites not produced (somewhat produced in opacifovea).

Distribution: Japan (Hokkaido, Honshu, Shikoku, Kyushu, Sado Is., Tsushima Is., Yakushima Is.). (Fig. 9 for yamato, Fig. 10 for opacifovea)

Floral records: A total of 1878 females and 1517 males have been collected on 36 flowering plants. Out of them 1835 females $(97.7 \%)$ and 1468 males (96.8\%) have been collected on Brassica napus L. (In this paper scientific names of plants are followed Coloured Illustration of Herbaceous Plants of Japan by S. Kitamura et al. (1957-1964)).

Flight records : Females have been taken from March 20 to August 1-4, and males from March $\mathrm{S}$ to May 30. In Kyushu most data of our collection are from late March to late April. However, small samples have been taken from late May to mid June in Fukuoka and Tsushima Is. It may be probable that a small number of populations emerge as a second generation.

Type material : Holotype female (Type No. 2422, Kyushu Univ.), Kuroubaru, Chikuho-machi, Fukuoka Pref., 7. iv. 1975 (0. Tadauchi). Paratypes: 
70 females and 252 males, same data as holotype. We have examined a total of 4035 specimens (2195 females and 1840 males) of this species including the type materials. The female ratio of yamato to opacifovea is 2195: 76 and the male one is 1840: 52 in the present study.

TYPE DEPositoRy: The type is preserved in the collection of the Entomological Laboratory, Faculty of Agriculture, Kyushu University.

Remarks: This is a sibling species of Andrena(Simandrena) opacifovea Hirashima. The female of this new species is primarily separated from opacifovea by the entire subapical margin of the pronotum as stated above. In addition, the pronotal line is absent, the mesoscutum less tessellate and more shiny with smaller, weaker, and sparser punctures, and the metasomal terga with smaller and weaker punctures. The male of this new species is separable from that of opacifovea in having the 7 th sternum with apical lobes narrow, the 8th sternum with apical lobe slender, and the dorsal lobes of gonocoxites of genitalia are not projected.
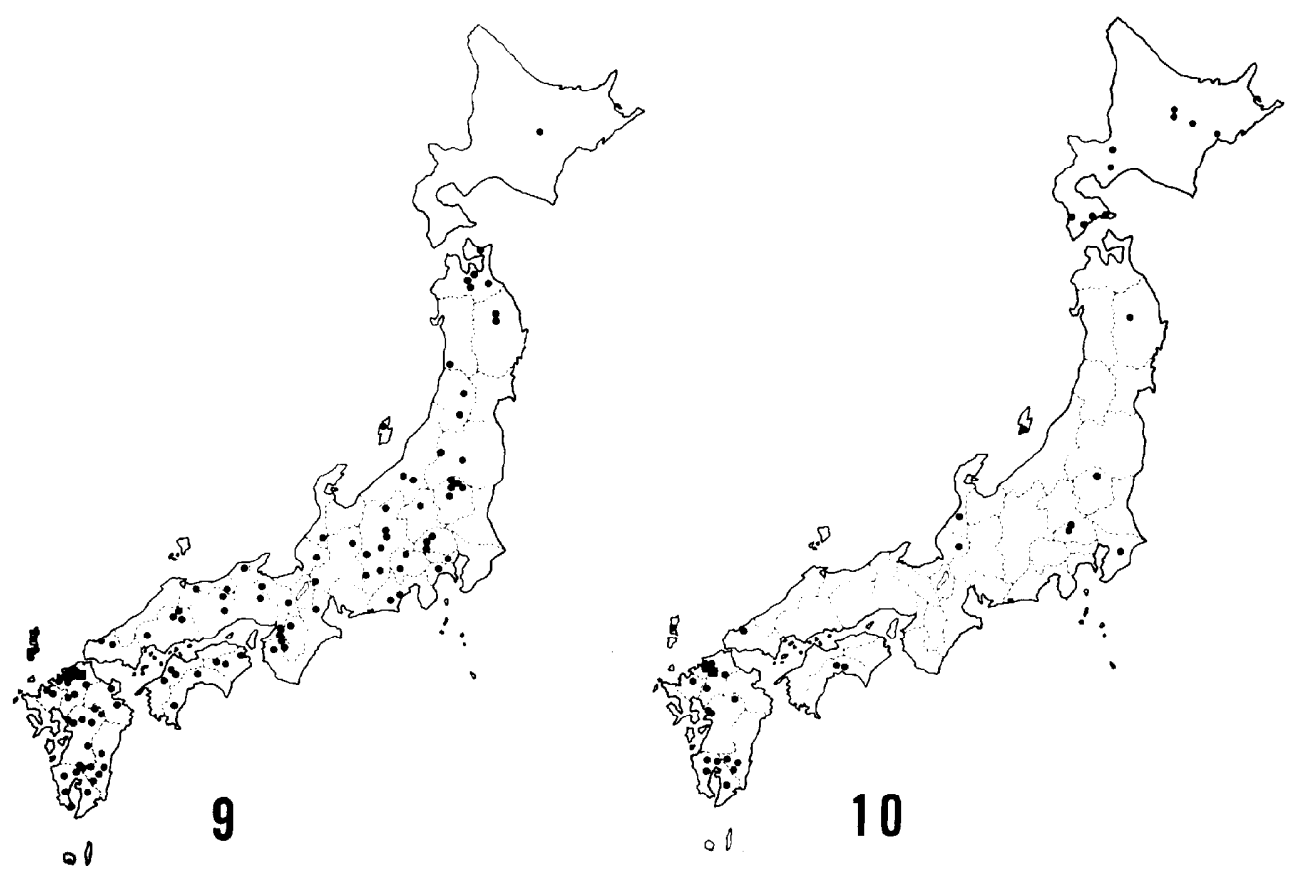

Figs. 9 and 10. Maps showing the distribution of Andrena (Simandrena) yamato, new species (9), and Andrena (Simandrena) opacifovea opacifovea Hirashima (10) based on the present study. A square indicates the type locality. 
Andrena (Simandrena) opacifovea austroinsularis, new subspecies

Distribu tion: Japan (Amami Is .).

Floral record: Castanopsis cuspidata Schottky var. sieboldii Nakai.

Flight records: We have only two females, which were taken in mid April.

Type material: Holotype female (Type No. 2423, Kyushu Univ.), Hatsuno, Amami-Oshima, 12. iv. 1976 (H. Makihara). Paratype: female, same locality as holotype, 10. iv. 1980 (K. Ôhara).

TyPE DEPOSITORY: The type is preserved in the collection of the Entomological Laboratory, Faculty of Agriculture, Kyushu University.

REMARKS: The female of this new subspecies is easily separated from the nominate subspecies in the combination of the following characters: the vertex with blackish hairs, the facial fovea blackish above; the subapical margin of pronotum very weakly emarginate in the middle, the mesoscutum covered with blackish hairs, the mesepisternum not shagreened but weakly tessellate with weak punctures, the tibia1 scopa pale brownish dorsally, and the caudal fimbria deep brownish, propodeal enclosure weakly wrinkled, 1st metasomal tergum distinctly tessellate or lineolate, nearly impunctate or with microscopical punctures.

Andrena (Simandrena) kerriae Hirashima

Andrena (Simandrena) kerriae Hirashima, 1965, J. Fac. Agr., Kyushu Univ., 13: 499, female. (Description)

Andrena (Simandrena) kerriae Hirashima, 1966, J. Fac. Agr., Kyushu Univ., 14: 106, female. (Key)

The male description of this species, which is new to science, is given below.

Male : Length 7-8 mm.

Integumental color: As in female except metasomal terga and sterna more widely subhyaline apically.

Pubescence: Head and thorax with long, dense, whitish hairs, those on clypeus abundant, white ; head and thorax without mixed brownish or blackish hairs; leg with white hairs except for inner surface of tarsus slightly yellowish; metasomal tergum 1 with more or less long and dense white hairs anteriorly, terga 2-4 with rather short, fine, pale hairs, with apical whitish hair bands poorly developed; tergum 5 with sparse, whitish hairs posteriorly; tergum 6 with sparse, whitish hairs; sterna 1-5 with sparse, short, suberect, whitish hairs.

Structure: Process of labrum small, twice as broad as long, transverse with apical margin slightly emarginate medially. Clypeus with apical half densely tessellate and basal half shagreened, with shallow, moderate-sized, 
close punctures. Lower paraocular area nearly smooth, weakly shiny with somewhat rough punctures. Vertex broadly round in frontal view. Malar space linear. Mandible rather short. Scape slightly longer than flagellar segment 1 plus 2; flagellar segment 1 slightly longer than segment 2 . Eyes with inner margins divergent above.

Pronotum weakly tessellate with weak, sparse punctures; pronotum with lateral suture weakly indicated, moderately long; anterior margin of pronotum not emarginate medially. Mesoscutum densely tessellate with indistinct, somewhat dense punctures posteriorly, nearly shagreened anteriorly. Propodeal enclosure well indicated, large, strongly wrinkled all over; dorsal face of propodeum and corbicular area shagreened with rough punctures. Mesepisternum roughly shagreened with rough punctures.

Legs slender as usual.

Metasomal terga very weakly, finely tessellate, weakly shiny, with dense, more or less large and strong punctures; apical depressions of terga not

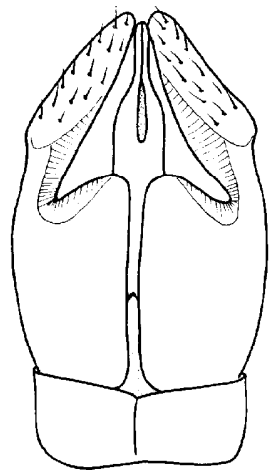

11

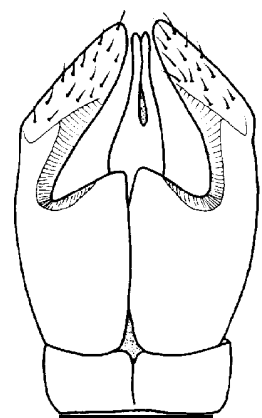

15

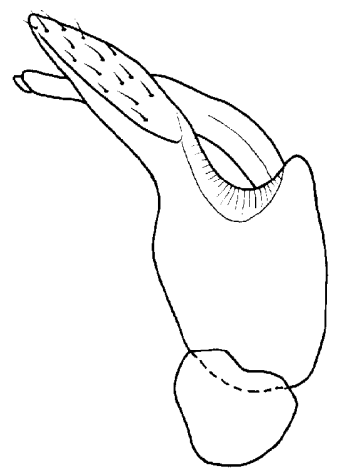

12

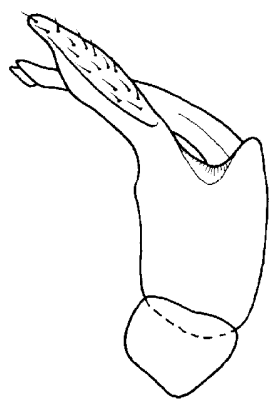

16

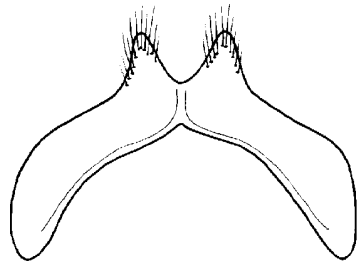

17

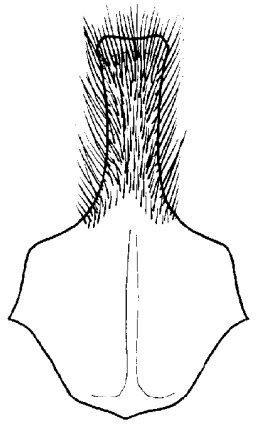

14

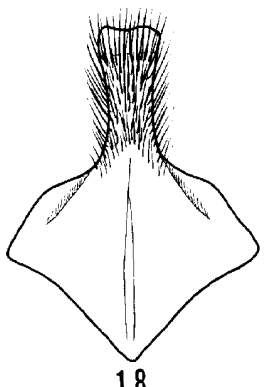

18

Figs. 11-18. Genital capsules and associated structures of Andrena(Simandrena) kerriae Hirashima (11-14), and Andrena (Simandrena) nippon, new species (15-18). 11 and 15: dorsal view of genital capsules, 12 and 16: lateral views of the same, 13 and 17: 7th sterna, 14 and 18: 8th sterna. 
sharply indicated. Metasomal sterna finely tessellate with microscopical punctures. Sternum 7 (Fig. 13) with apex deeply emarginate, V-shaped, apical lobes moderately long with sparse hairs. Sternum 8 (Fig. 14) with apical lobe longer than basal region, apex slightly expanded. Genital capsule (Figs. 11-12) with dorsal lobes of gonocoxites moderately short with apex rounded; lateral arm of gonocoxite with short, sparse hairs.

Distribution : Japan (Hokkaido, Honshu, Shikoku, Kyushu). (Fig. 19)

Floral records : In addition to the plants recorded by Hirashima (1965), we have collected this species on the following plants: Taraxacumofficinale Weber, Capsella bursa-pastoris Medicus, Potentilla kleiniana Wight et Arn.

Flight records: Collection dates for females range from April 9 to June 3, for males range from April 15 to May 30. In western Japan most collection dates are from mid April to early May, in nothern Japan from late May to early June.

Specimens examined: (Excluded the specimens recorded by Hirashima (1965)) Hokkaido: 3 females and 7 males, Tsukissapu, Sapporo, 24-30. v. 1965 (Watanabe) ; Honshu : 3 females, Magome, Yamaguchi-mura, Nagano Pref., 15. v. 1975 (0. Tadauchi) ; 3 females and 3 males, Hatahoko, Mt. Norikura, Gifu Pref., 8. v. 1976 (0. Tadauchi) ; 1 female, Inokuchi, Nakai, Kanagawa Pref., 8. v. 1975 (0. Tadauchi) ; 1 female, Kotaki, Kisakata, Akita Pref., 25. v. 1975 (0. Tadauchi) ; 1 female, Kuriyagawa, Morioka, Iwate Pref., 28. v. 1964 (Y. Maeta); 2 females, Hagi, Yamaguchi Pref ., 23-26. iv. 1960 (K. Nohara) ; Shikoku: 1 male, Ochiai, Kuma, Ehime Pref., 15. iv. 1976 (0. Tadauchi) ; Kyushu: 3 females, Hikosan, Fukuoka Pref ., 5. v. 1973 (0. Tadauchi) ; 2 females, Hokuzan Dam, Ozeki, Saga Pref., 13. iv. 1973 (0. Tadauchi and J. Emoto) ; 1 female, same locality as above, 28. iv. 1973 (0. Tadauchi).

\section{Andrena (Simandrena) nippon, new species}

Andrena (Simandrena) kerriae Hirashima, 1965, J. Fac. Agr., Kyushu Univ., 13: 499, female, in part. (Description)

Female : Length 8-9 mm.

Integumental color: Flagellar segments 3-10 dark brown below; metasomal terga and sterna brownish subtransparent apically.

Pubescence: Hairs on head not specially dense, pale to deep fulvous; facial fovea brownish (fulvous in kerriae); hairs on mesoscutum pale to deep fulvous, not mixed with fuscous hairs, short, not dense; propodeal corbicula very well developed with dorsal fringe composed of very long, dense, well curled, yellowish hairs ; dorsal face of propodeum with fulvous hairs, not dense; trochanteral floccus whitish, imperfect, scanty; tibia1 scopa scanty, short ; metasomal tergum 1 free of hairs medially; terga 2-4 with whitish to yellowish, dense, compact hair bands, band of 2 nd broadly interrupted, and that of $3 \mathrm{rd}$ 
narrowed medially ; caudal fimbria brownish (golden in kewiae) ; metasomal sterna 1-2 with short, dense, erect hairs medially, sterna 2-5 with short, suberect, pale hairs posteriorly, with apical fringe very short.

Structure: Process of labrum moderate in size, more than three times as broad as long (twice as broad as long in kewiae), broadly round. Clypeus rather well convex, without or with a longitudinal, shiny, impunctate median space (shagreened impunctate space in kewiae); clypeus smooth, shiny with large, strong, dense punctures (weakly shagreened with coarse, large, close punctures in kerriae). Lower paraocular area nearly smooth with strong, dense punctures. Genal area slightly broader than eye seen in profile, with minute punctures crowded near eye, shagreened posteriorly. Facial fovea with upper end occupying more than two thirds of ocellocular space (nearly two thirds in kerriae). Vertex round in frontal view. Malar space rather linear, narrow. Mandible short. Scape longer than flagellar segments 1-3, flagellar segment 1 nearly as long as segments 2 plus 3. Eyes with inner margins subparallel.

Pronotum weakly tessellate, with weak, sparse punctures ; pronotum with lateral suture slightly developed, rather long, without humeral angle and lateral lugulae, subapical margin of pronotum not emarginate. Mesoscutum

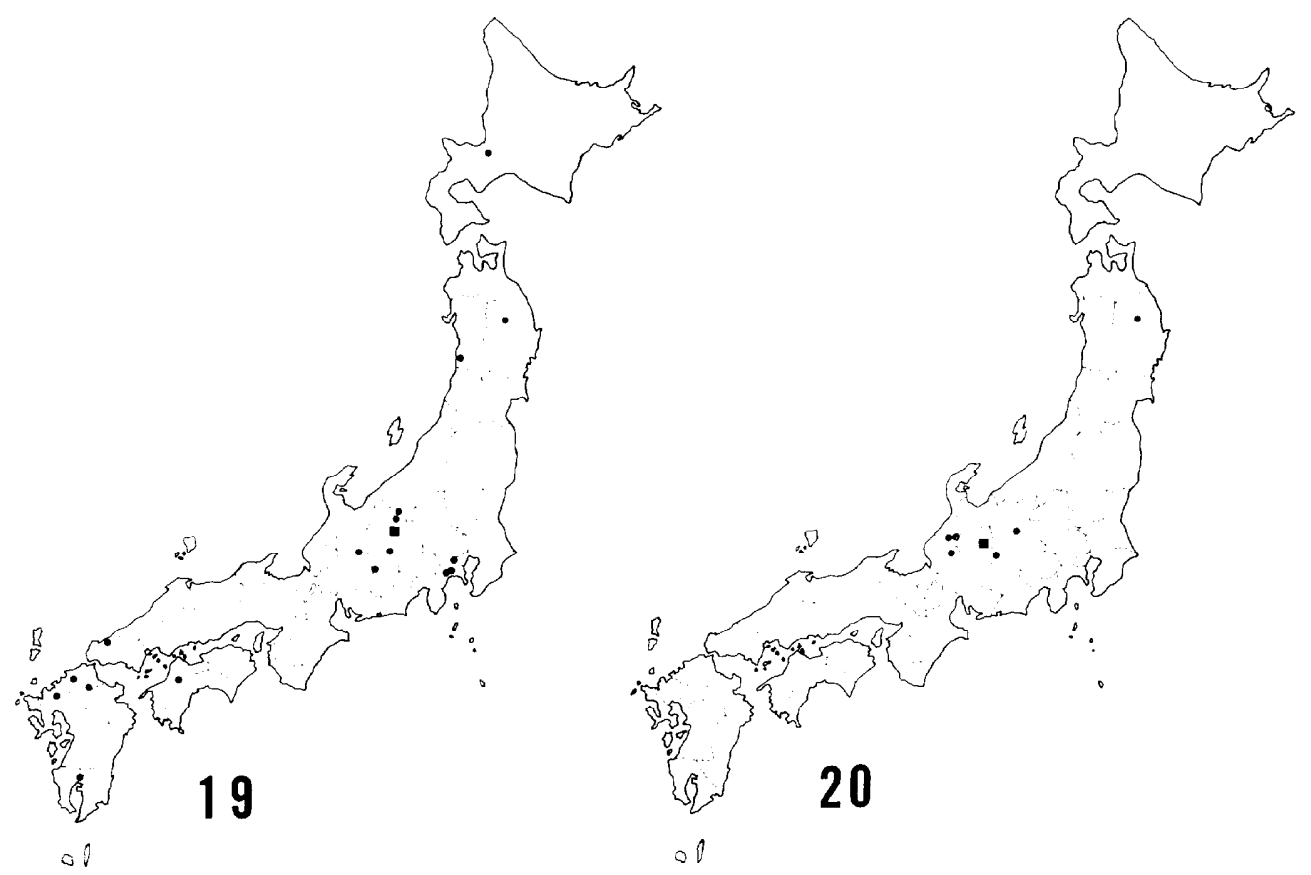

Figs. 19 and 20. Maps showing the distribution of Andrena(Simandrena)kerriae Hirashima (19) and Andrena (Simandrena) nippon, new species (20) based on the present study. A square indicates the type locality. 
weakly tessellate with strong, dense, medium-sized punctures (slightly sparser than in kerriae). Propodeal enclosure moderate in size, well defined, rugose basally, densely tessellate apically, not wrinkled (distinctly wrinkled all over in kerriae); dorsal face of propodeum roughened, corbicular area densely tessellate. Mesepisternum weakly tessellate with punctures anteriorly, densely tessellate posteriorly.

Leg with middle basitarsus slightly expanded medially, hind basitarsus subparallel ; hind tibia short, widened apically.

Metasomal tergum 1 smooth, shiny with punctures slightly sparser and weaker than in kewiae, terga 2-4 weakly tessellate with punctures slightly sparser than in kewiae on basal areas. with sparse, weak punctures on apical areas; apical depressions of terga moderately indicated. Pygidial plate blunt apically, with median area well raised, densely tessellate. Sternum 1 weakly tessellate with very weak, small punctures, with $U$-shaped median emargination; sterna 2-6 weakly tessellate with weak, dense punctures on basal areas, more densely and strongly tessellate on apical areas; apical depressions of sterna well indicated; gradulus indicated only on sternum 2.

Male : Length 7-8 $\mathrm{mm}$.

Agrees with description of female except as follows (excluding usual sexual differences) : hairs on head dense, pale, mixed with much brownish to blackish ones on paraocular area, vertex and genal area; hairs on clypeus not abundant as in kerriae; metasomal tergum 1 with more or less and dense, pale yellowish hairs anteriorly, terga 2-5 with rather short, blackish hairs, with apical hair bands whitish, poorly developed; tergum 5 with sparse, yellowish hairs apically; tergum 6 with sparse, yellowish hairs; process of labrum broader than kerriae, transverse with apical margin slightly emarginate; scape longer than flagellar segments 1 plus 2; flagellar segment 1 as long as segment 2, slightly shorter than segment 3; mesoscutum weakly tessellate anteriorly and laterally, smooth and shiny medially with sparse, moderatesized, strong punctures; metasomal terga smooth and shiny (weakly tessellate in kerriae) with more or less large and strong punctures, sparser than in kewiae; sternum 7 (Fig. 17) with apex deeply emarginate, V-shaped, apical lobes moderately long, with sparse, long hairs; sternum 8 (Fig. 18) with apical lobe shorter than basal region, apex slightly expanded; genital capsule (Figs. 15-16) with dorsal lobes of gonocoxites moderately short with apex less rounded than in kewiae.

Distribution: Japan (central and northern Honshu). (Fig. 20)

This species is known to occur from central (Ishikawa, Fukui, Gifu, and Nagano Prefs.) and northern Honshu (Iwate Pref.).

Floral records: A total of 35 females have been taken on the following 
flowers : Brassica napus L. ; Capsella bursa-pastoris Medicus ; Taraxacum albidum Dahlst.

Flight records: Collection dates for females range from May 7 to May 14 and from July 21 to August 25, for males range from July 20 to July 30. It seems probable that this species has two generations in a year.

Type Material: Holotype female (Type No. 2424, Kyushu Univ.) Hatahoko, Mt. Norikura, Gifu Pref., 8. v. 1976 (0. Tadauchi). Paratypes $\vdots 30$ females, same data as holotype; 2 females, Ohtaki, Mt. Ontake, Nagano Pref., 14. v. 1976 (0. Tadauchi) ;1 female, Sanjiro, Utsukushigahara, Nagano Pref., 7. v. 1961 (Y. Hirashima) ; 1 female, Shiramine-mura, Ishikawa Pref., 21. vii. 1949 (I. Togashi); 2 females, Kuriyagawa, Morioka, Iwate Pref., 12. v. 1964 (Y. Maeta); 1 female, Mt. Hakusan, 31. vii. 1962 (A. Nakanishi) ;1 female, Mt. Hakusan, Ishikawa Pref., 2. viii. 1960 (Y. Haneda) ; 2 females, Akausagiyama, Ohno, Fukui Pref., 25. viii. 1976 (Y. Haneda) ; 2 males, same locality as above, 20. vii. 1975 (Y. Haneda) ; 1 male, Mt. Rokuman, Ishikawa Pref., 30. vii. 1959 (I. Togashi).

Type Depository: The type is preserved in the collection of the Entomological Laboratory, Faculty of Agriculture, Kyushu University.

REMARKs: This new species closely resembles Andrena (Simandrena) kerriae Hirashima. The new species is distinguished from kerriae by the process of labrum broader, the clypeus with median longitudinal area smooth and shiny, the propodeal enclosure rugose only basally, and the metasomal terga with weaker, smaller and sparser punctures. In addition, the female caudalfim. bria darker (brownish) than in kewiae (golden), and the hairs on the male clypeus are sparser and darker (pale mixed with black) than kerriae (very dense and white). 